\title{
A Study on the Range of Defense for Handball Goalkeeper in a 9-meter Jump Shot
}

\author{
Jonghyun Yang ${ }^{1}$ and Junwoo Kwon ${ }^{2 *}$ \\ ${ }^{1}$ Department of Physical Education, Incheon National University, Incheon, Korea \\ ${ }^{2}$ Department of Physical Education, Seoul National University, Seoul, Korea
}

\author{
Article Info \\ Received 2021.06.25. \\ Revised 2021.09.23. \\ Accepted 2021.09.28. \\ Correspondence* \\ Junwoo Kwon \\ kkjj418@snu.ac.kr

\section{Key Words} \\ Handball, \\ Goalkeeper, \\ Range of defense, \\ 9-meter jump shot \\ 이 논문 또는 저서는 2019년 대한민국 \\ 교육부와 한국연구재단의 인문사회분야 \\ 신진연구자지원사업의 지원을 받아 수행된 \\ 연구임 (NRF-2019S1A5A8037896).
}

PURPOSE The purpose of this study is to examine the goalkeeper's area of defense and how the range varies depending on the relative position of the goal, goalkeeper, and ball in a 9-meter jump shot during handball matches. METHODS Data was collected from seven qualifying divisions in mens handball from the 99th National Sports Festival in Korea. A total of 231, 9-meter jump shots were analyzed with the goalkeeper's area of defense measured from the point the ball left the shooter's hand and calculated based on the relative position of the goal, goalkeeper, and ball. Video analysis was conducted using the Kwon3D 3.01 program and three-dimensional coordinates calculated using the DLT method. RESULTS First, dimension of handball goals measure $3 \mathrm{~m}$ wide and $2 \mathrm{~m}$ high, however, results show that goalkeeper's actual area of defense was narrower than the width of the goal posts, while vertically, area exceeded the height of the cross bar. Second, if the goalkeeper defended the striker's shot from the side rather than from the front, the goalkeeper's defense range was higher for the opposite side of the goal post than the near side of the goal post. CONCLUSIONS Key factors influencing goalkeeper's area of defense include height of shot and position of goalkeeper. Results also indicate that vertical movements are more important than horizontal movements for goalkeepers in handball thus such implementation in training may lead to performance enhancement.
서론

경쟁은 스포츠의 대표적인 특징 중 하나이다. 스포츠는 본인의 한계를 극복하기 위해 스스로와 경쟁하고, 갈고닦은 기량의 우열을 가리기 위 해 상대방과 경쟁한다. 일부 경쟁 스포츠에는 골키퍼라는 포지션이 존 재한다. 골키퍼는 다른 필드 플레이어와 구분되는 독특한 특성이 있고 골키퍼만의 고유 기술을 가진다. 골키퍼의 실수는 실점과 직결되고, 실 점은 승패에 직접적 영향을 주기에 골키퍼라는 포지션은 중요하다(김재 희 외, 2015). 골키퍼 수는 다른 포지션에 비해 적기 때문에 경험을 쌍아 숙련도를 높이기가 상대적으로 어렵고 선수교체의 빈도가 적다. 그렇기 에 골키퍼는 다른 포지션의 선수들에 비해서 더 긴 경기 경험을 가진다 (Sporis et al., 2009). 다시 말해서 골키퍼는 신인 선수가 선발출장이나 교체출전으로 실전 경험을 쌓을 기회가 타 포지션에 비해 매우 부족하 다. 따라서 골키퍼가 실전에서 좋은 실력을 발휘하기 위해서는 더욱 효 율적이고 효과적인 훈련방법이 요구된다.

골키퍼의 역할을 잘 수행하기 위해서는 방어기술, 판단력, 인지적 능 력, 상황 해결 능력, 심리적 강인함 등이 필요하다(이대택 외, 2007). 골
키퍼와 필드플레이어로 나누어진 구기종목의 경우 골키퍼의 경기력이 승패를 가르는 데 미치는 영향이 큰데, 이는 핸드볼에서도 마찬가지이 며 골키퍼는 수비의 핵심이다(김의진, 1995). 핸드볼 경기의 승패에 가 장 큰 영향을 주는 포지션은 골키퍼이며, 골키퍼 경기력 평가에 필요한 요인은 전체 방어율과 어시스트가 꼽혔다(홍정호, 박재현, 2016). 지금 까지 골키퍼라는 포지션이 가지는 중요성에 비해 골키퍼에 대한 체계적 인 분석은 부족하였다. 특히 골키퍼의 경기력과 기술 향상에 직접적으 로 영향을 주는 행동 분석 방법이나 분석자료들이 필요하다(김재희 외, 2015).

Yang \& Lee(2016)의 연구에 의하면 전방 9m 점프 슛을 방어하는 핸 드볼 골키퍼의 하단 방어율보다 상단 방어율이 높게 나타났다. 이러한 정보를 공격수가 알고 있다면 하단으로 슛을 더 많이 시도할 것이다. 반 대로 골키퍼가 이러한 사실을 인지한다면 하단 방어를 위해 수비 자세를 더욱 낮추거나, 하단 방어율 향상 훈련에 더욱 매진할 것이다. 이처럼 통 계적 분석의 활용은 핸드볼 공격수와 골키퍼의 경기력과 훈련 방향에 영 향을 미칠 수 있다.

만약에 특정 상황에서 공격 성공률이 더 높은 방향이 있거나, 반대로 


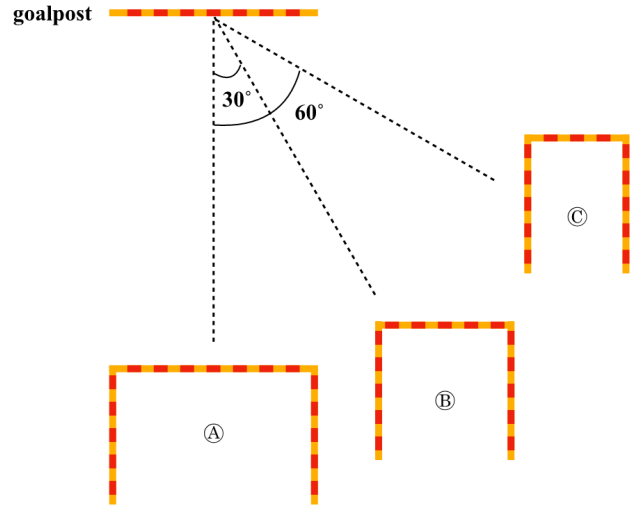

Fig. 1. Change of shooting range(width) according to shooting angle (A): front, (B): $30^{\circ}$, (C): $60^{\circ}$ )

골키퍼의 입장에서 더욱 방어에 치중을 해야 하는 위치가 있다면 어떻게 하겠는가? 골키퍼의 좌우 반응속도가 동일하다고 가정하였을 때 골키퍼 가 한쪽 측면으로 치우쳐서 방어를 한다면 공격수는 어느 방향으로 슛을 하겠는가? 아니면 골키퍼가 가운데에서 방어를 하지만, 한쪽을 더 잘 막 는다고 하면 공격수는 어느 방향으로 슛을 할 것인가? 두 상황 모두 공격 수는 골키퍼가 가장 막기 힘든 부분으로 슈팅을 할 것이다.

골키퍼의 방어 위치에 대한 연구(양종현, 천영진, 2015; Yang \& Lee, 2016; 양종현 외, 2019)들은 주로 정면에서 이루어지는 공격에 대한 골 키퍼의 방어에 대한 연구로 측면 상황에서 공의 높이와 골키퍼의 위치 에 대한 고려는 이루어지지 못하였으며, Yang et al.(2017)의 축구 연구 에서는 축구 골키퍼가 다이빙을 하지 않아도 되는 측면 상황에서의 반응 속도에 대해 알아보았지만, 골키퍼가 실제 방어를 해야 하는 범위에 대 한 언급은 하지 않고 있다.

핸드볼, 축구, 하키와 같이 골키퍼가 존재하는 스포츠에서 사용되는 골대는 직사각형이다. 좌· 우, 상-하가 대칭이 되기 때문에 골키퍼는 골 대의 중앙에서 방어를 하며, 공격수는 골키퍼의 행동이 가장 나중에 다 다를 것으로 예상되는 곳으로 슛을 하려고 노력한다. 공격수가 골대의 정면이 아닌 측면에서 슛을 한다면 시각적으로도 슈팅 가능 폭이 줄어든 다는 것을 알 수 있다〈Fig. 1 〉.

〈Fig. 1〉은 골대 높이 $(2 \mathrm{~m})$ 와 동일한 높이에서 슈팅이 이루어 졌을 경 우 공격 가능 범위를 보여주고 있다. 만약 슈팅이 높이 $2 \mathrm{~m}$ 이상에서 이 루어진다면 골키퍼가 막아야 하는 방어 범위의 어떻게 변할까? 〈Fig. 1〉 과 같이 슈팅 각도가 변했을 때 공격 가능 범위의 폭만 변할것인가? 아니 면 공격 가능 높이도 변하는가? 현재까지 슈팅 위치(높이, 각도, 거리)와 골키퍼의 위치를 고려한 슈팅 가능 범위에 대한 연구는 없었으며, 슈팅 높이와 골키퍼의 위치에 따라 골키퍼의 방어 폭과 높이가 달라진다는 것 을 알려주는 교재도 없었다. 이러한 정보는 골키퍼가 실전 상황에 대비 해 효율적인 훈련을 할 수 있는 기초 정보가 될 것이다.

따라서 본 연구는 골대, 골키퍼, 공의 상대적인 위치에 따라 골키퍼가 방어를 해야 하는 범위가 어떻게 변하는지를 알아보고 이를 통해 골키퍼 의 효율적이고 효과적인 연습 방법을 제안하고자 한다.

\section{연구방법}

\section{연구대상과 범위}

핸드볼 경기에서는 매우 다양한 형태의 슛을 관찰할 수 있지만 본 연구 는 핸드볼 경기 중 가장 일반적으로 나타나는 $9 \mathrm{~m}$ 내외에서 던지는 점프 슛으로 한정하여 분석하였다. $9 \mathrm{~m}$ 점프 슛 상황에서 골대, 골키퍼, 공의 상대적인 위치를 파악하기 위하여 제99회 전국체육대회 남자 핸드볼 일 반부 예선전 7경기를 직접 촬영하였다.

\section{측정 항목 및 방법}

\section{1. 실험도구}

본 연구에서는 공간 정의를 위한 통제점틀 $(1 \mathrm{~m} \times 1 \mathrm{~m} \times 3 \mathrm{~m})$, 동작 촬 영을 위한 디지털 비디오 카메라 4대, 그리고 데이터 처리를 위한 컴퓨 터를 사용되었다. 영상분석은 Kwon3D 3.01(Young-Hoo Kwon \& Visol, Inc., Korea) 프로그램을 사용하였으며, 자료 처리를 위해 Excel 16.49(Microsoft Inc., USA) 프로그램을 사용하였다.

\section{2. 실험 절차 및 방법}

1) 영상 장비 설치

4 대의 디지털 비디오 카메라를 관중석에서 약 45 도 각도로 골키퍼를 바라볼 수 있게 설치하였으며, 각각의 디지털 비디오 카메라는 골대, 골 키퍼 위치, 슈팅 위치를 모두 촬영할 수 있도록 설치하였다〈Fig. 2〉. 비 월주사방식(interace scan) $30 \mathrm{frames} / \mathrm{sec}$ 로 촬영하였으며, 분석은 60 fields/sec으로 진행하였다.

\section{2) 통제점틀 설치 및 촬영}

대회가 열리는 핸드볼 코트에서 실제 슈팅과 골키핑 공간을 모두 포함 할 수 있도록 넓이 $15 \mathrm{~m}$, 길이 $10 \mathrm{~m}$, 높이 $3 \mathrm{~m}$ 공간에 $1 \mathrm{~m} \times 1 \mathrm{~m} \times 3 \mathrm{~m}$ 크기의 통제점틀을 각 꼭지점에 설치 후 촬영하였다〈Fig. 2〉. 통제점틀 설치 및 촬영은 대한핸드볼협회의 허락을 득한 후 시합 전 실시하였다.

3) 통제점 및 인체 좌표점의 좌표화

실공간의 좌표 설정을 위해 실험 공간을 포함하도록 설치된 4 개의 통 제점틀 속에 동일한 간격으로 표시된 40 개의 통제점을 좌표화 하였다. 이때 오차를 최소화하기 위하여 통제점을 5 번 좌표화 한 후 평균값을 사 용하였다. 실공간의 전역 좌표계(global reference)는 골키퍼를 기준으 로 골대 좌측 하단을 원점으로 하여 골키퍼의 우측 방향을 X축, 전방을 $\mathrm{Y}$ 축으로 설정하고 $\mathrm{Z}$ 축은 두 벡터의 외적(cross product)으로 설정하였 다. 본 연구에서는 $9 \mathrm{~m}$ 점프 슛 상황에서 슈터의 손에서 공이 떨어지는 순간 골키퍼의 방어 위치, 공의 위치, 골대 모서리까지 총 6지점을 디지 타이징하여 좌표화 하였다.

4) 동조

각 카메라를 통해 확보한 영상 자료는 공격수가 공을 던질 때 손에서 공이 떨어지는 시점을 기준으로 동조하였다.

\section{5) 3 차원 좌표의 계산}

3차원 좌표의 계산은 DLT방법을 이용하였다(Abdel-Aziz \& Karara, 1971; Walton, 1981). 우선 각 카메라로부터 획득한 통제점의 2차원 좌 표값과 이들의 실제 공간상의 위치 정보로부터 16개의 DLT계수를 산출 하여 3차원 공간의 공간좌표를 형성하고, 이를 이용하여 골키퍼(머리), 골대, 공의 3 차원 좌표를 계산하였다. 

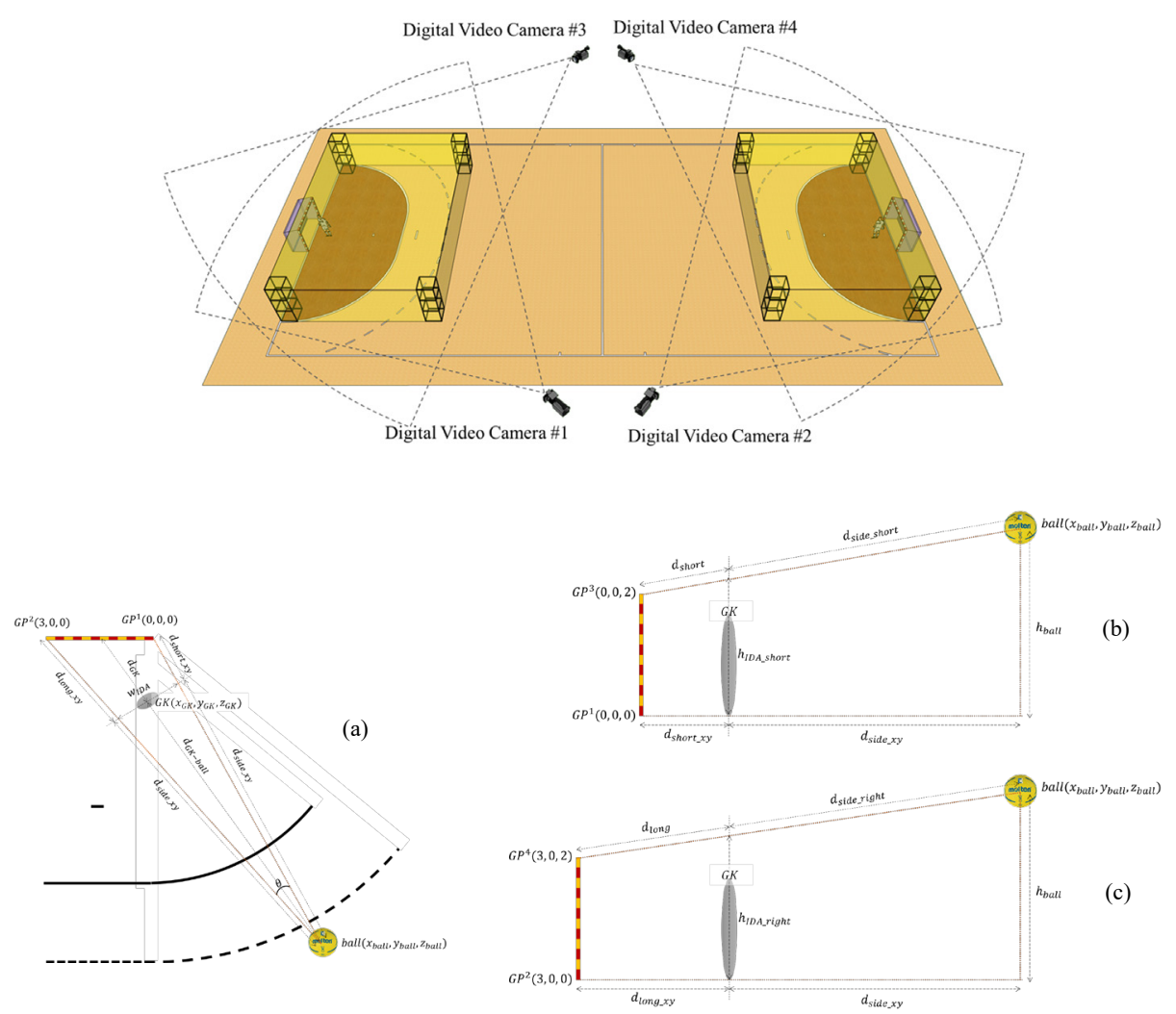

Fig. 2. Digital camera and control point frame layout

Fig. 3. Diagram for calculating goalkeeper defense height in diagonal shooting

(a) The position of the goalpost, goalkeeper, and ball on the $x y$ plane and the corresponding reference angle and distance

(b) Goalkeeper defense height in the side of the near goalpost (c) Goalkeeper defense height in the side of the far goalpost

\section{변인 산출 방법}

영상 분석을 통해 얻게 된 슈팅 릴리스 시점에서의 골키퍼 방어 위치, 공 의 위치, 골대 모서리 좌표값을 확인하여 슛을 하는 공의 위치에서의 유 효슈팅 가능 폭(너비), 먼 쪽 골대 방향으로 유효슈팅 가능 높이, 가까운 쪽 골대 방향으로 유효슈팅 가능 높이를 산출하였다. 〈Fig. 3〉은 사선에 서 슈팅시 공, 골키퍼, 골대의 관계를 보여주는 그림이다. 가까운 쪽 골 포스트 하단을 원점으로 하고, $1 \mathrm{~m}$ 의 거리를 좌표 1 로 정의하였다. 공격 수의 손에서 공이 떨어지는 시점에서 공의 위치를 $\operatorname{ball}\left(x_{\text {ball }}, y_{\text {ball }}, z_{\text {ball }}\right)$,
골키퍼의 위치를 $G K\left(x_{G K}, y_{G K}, z_{G K}\right)$, 골대 중앙에서 골키퍼까지의 거리 를 $d_{G K}$, 먼 쪽 골대에서 골키퍼 방어선까지 거리를 $d_{\text {long }}$, 가까운 쪽 골대 에서 골키퍼 방어선까지 거리를 $d_{\text {short }}$, 골키퍼 방어선에서 공까지 거리 를 $d_{\text {side }}$, 먼 쪽 골대에서 골키퍼 방어선까지 수평 거리를 $d_{\text {long }_{x y}}$, 가까운 쪽 골대에서 골키퍼 방어선까지 수평 거리를 $d_{s h o r t}$, 골키퍼 방어선에서 공까지 수평 거리를 $d_{\text {side }}$ 라고 정의하였을 경우 골키퍼 방어 너비 $w_{I D A}$

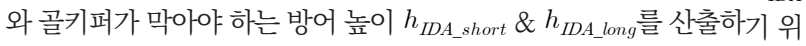
한 공식은 아래와 같다.

$$
\begin{aligned}
& d_{G K}=\sqrt{\left(x_{G K}-1.5\right)^{2}+\left(y_{G K}\right)^{2}}, \quad d_{G K-\text { ball }}=\sqrt{\left(x_{G K}-x_{\text {ball }}\right)^{2}+\left(y_{G K}-y_{\text {ball }}\right)^{2}} \\
& \theta=\cos ^{-1}\left[\frac{x_{\text {ball }}\left(3-x_{\text {ball }}\right)+y_{\text {ball }}\left(-y_{\text {ball }}\right)+z_{\text {ball }}\left(-z_{\text {ball }}\right)}{\left.\left.\sqrt{\left(x_{\text {ball }}-\left(3-x_{\text {ball }}\right)\right)^{2}+\left(y_{\text {ball }}-\left(-y_{\text {ball }}\right)\right)^{2}+\left(z_{\text {ball }}-\left(-z_{\text {ball }}\right.\right.}\right)\right)^{2}}\right] \\
& d_{\text {side_xy }}=\frac{d_{G K-\text { ball }}}{\sin \frac{\theta}{2}}, \quad d_{\text {short_xy }}=\sqrt{x_{\text {ball }}^{2}+y_{\text {ball }}^{2}}-d_{\text {side_xy }}, \quad d_{\text {long_x } x y}=\sqrt{\left(x_{\text {ball }}-3\right)^{2}+y_{\text {ball }}^{2}}-d_{\text {side_x } x y} \\
& w_{I D A}=2 \times \tan \frac{\theta}{2} \times d_{G K-\text { ball }} \\
& h_{I D A \_s h o r t}=\left(h_{\text {ball }}-2\right)\left(\frac{d_{\text {short_xy }}}{d_{\text {short_xy }}+d_{\text {side_xy }}}\right)+2, \quad h_{I D A \_l o n g}=\left(h_{\text {ball }}-2\right)\left(\frac{d_{\text {long_xy }}}{d_{\text {long_xy }}+d_{\text {side_xy }}}\right)+2
\end{aligned}
$$




\section{연구결과}

\section{$9 \mathrm{~m}$ 점프 슛 상황에서 공과 골키퍼의 위치}

〈Fig. 4〉는 총 231개의 $9 \mathrm{~m}$ 점프 슛 상황에서 공이 공격수의 손에서 떨 어지는 순간, 공의 위치와 골키퍼의 위치를 표시한 그림이다. $9 \mathrm{~m}$ 점프 슛의 경우 골라인 중앙에서 평균적으로 $9.403 \mathrm{~m}(\mathrm{SD}=.825)$ 떨어진 곳 에서 이루어졌다. 추가적인 분석을 위해 〈Fig. 4〉와 같이 골라인의 정가 운데에서 좌측으로 $2 \mathrm{~m}$ 바깥에서 발생한 슈팅을 좌측 슛 $(\mathrm{n}=44)$, 우측 으로 $2 \mathrm{~m}$ 바깥에서 발생한 슈팅을 우측 슛 $(\mathrm{n}=60)$, 좌우측 $2 \mathrm{~m}$ 안쪽에서 발생한 슈팅을 중앙 슛 $(\mathrm{n}=127)$ 으로 구분하였다. 좌우측 외곽에서 발생 한 $9 \mathrm{~m}$ 점프 슛의 경우 골라인 중앙을 기준으로 평균적으로 $20.76^{\circ}(\mathrm{n}=$ 104) 측면에서 발생하였다.

우측 $9 \mathrm{~m}$ 점프 슛의 경우 골라인을 기준으로 평균적으로 우측으로 $3.244 \mathrm{~m}(\mathrm{SD}=.899)$, 전방으로 $8.817 \mathrm{~m}(\mathrm{SD}=1.110)$ 떨어진 지점에서 슛 이 이루어졌으며, 골키퍼는 골라인 중앙을 기준으로 평균적으로 우측으 로 $0.733 \mathrm{~m}(\mathrm{SD}=.401)$, 전방으로 $1.741 \mathrm{~m}(\mathrm{SD}=.723)$ 떨어진 지점에서 방어를 하였다. 중앙 $9 \mathrm{~m}$ 점프 슛의 경우 골라인 중앙을 기준으로 평균 적으로 우측으로 $0.079 \mathrm{~m}(\mathrm{SD}=1.147)$, 전방으로 $9.314 \mathrm{~m}(\mathrm{SD}=.818)$ 떨 어진 지점에서 슛이 이루어졌으며, 이때 골키퍼는 골라인 중앙을 기준 으로 평균적으로 우측으로 $0.044 \mathrm{~m}(\mathrm{SD}=.350)$, 전방으로 $1.558 \mathrm{~m}(\mathrm{SD}$ $=.573$ ) 떨어진 지점에서 방어를 하였다. 좌측 $9 \mathrm{~m}$ 점프 슛의 경우 골라 인 중앙을 기준으로 평균적으로 좌측으로 $3.273 \mathrm{~m}(\mathrm{SD}=.972)$, 전방으로 $8.725 \mathrm{~m}(\mathrm{SD}=1.126)$ 떨어진 지점에서 슛이 이루어졌으며, 골키퍼는 골 대 중앙을 기준으로 평균적으로 좌측으로 $0.679 \mathrm{~m}(\mathrm{SD}=.277)$, 전방으로 $1.614 \mathrm{~m}(\mathrm{SD}=.597)$ 떨어진 지점에서 방어를 하였다.

\section{$9 \mathrm{~m}$ 점프 슛 상황에서 유효슈팅 가능 각도와 골키퍼의 방어 범위}

$9 \mathrm{~m}$ 점프 슛의 유효슈팅 가능범위가 곧 골키퍼의 방어범위가 된다. 골키 퍼의 방어범위는 슛 상황에서 공과 골대(가까운 골대와 먼 골대 각각) 사 이의 거리와 각도 그리고 공의 높이를 통하여 산출할 수 있다. 골키퍼가 방어해야 하는 범위와 높이를 산출할 때는 평균치가 아니라 실제 핸드볼 시합에서 발생하였던 모든 경우의 수를 고려하여 최대값을 활용하였다.

좌측 $9 \mathrm{~m}$ 점프 슛은 최대 $2.763 \mathrm{~m}$ 높이에서 이루어졌고 골키퍼는 슈 팅방향을 향해 골라인 가운데에서 평균 $1.909 \mathrm{~m}(\mathrm{SD}=.779)$ 위치에서 방 어하였다. 공과 골키퍼 사이의 거리는 평균 $7.568 \mathrm{~m}(\mathrm{SD}=1.295)$ 이고 골 키퍼가 방어해야 할 좌우 범위는 최대 $2.646 \mathrm{~m}$ 이다. 방어해야 하는 높 이의 경우 가까운 쪽 골대의 경우 최대 $2.280 \mathrm{~m}$, 먼 쪽 골대의 경우 최대 $2.322 \mathrm{~m}$ 이다〈Table 1 .
중앙 $9 \mathrm{~m}$ 점프 슛 $(\mathrm{n}=127)$ 은 최대 $2.893 \mathrm{~m}$ 높이에서 이루어졌고 골키 퍼는 평균 $1.590 \mathrm{~m}(\mathrm{SD}=.594)$ 전방에서 방어하였다. 공과 골키퍼 사이 의 거리는 평균 $7.811 \mathrm{~m}(\mathrm{SD}=1.011)$ 이고 골키퍼가 방어해야 할 좌우 범 위는 최대 $2.777 \mathrm{~m}$ 이다. 방어해야 하는 높이의 경우 가까운 쪽 골대의 경우 최대 $2.250 \mathrm{~m}$, 먼 쪽 골대의 경우 최대 $2.289 \mathrm{~m}$ 이다〈Table 1 〉.

우측 $9 \mathrm{~m}$ 점프 슛은 최대 $2.765 \mathrm{~m}$ 높이에서 이루어졌고 골키퍼는 슈 팅방향을 향해 골라인 가운데에서 평균 $1.768 \mathrm{~m}(\mathrm{SD}=.610)$ 위치에서 방 어하였다. 공과 골키퍼의 거리는 평균 $7.637 \mathrm{~m}(\mathrm{SD}=.997)$ 이고 골키퍼가 방어해야 할 좌우 범위는 최대 $2.660 \mathrm{~m}$ 이다. 방어해야 하는 높이의 경우 가까운 쪽 골대의 경우 최대 $2.169 \mathrm{~m}$, 먼 쪽 골대의 경우 최대 $2.217 \mathrm{~m}$ 이다〈Table 1$\rangle$.

위의 내용을 참고하여 공격수의 슛을 막기 위해 골키퍼가 방어해야 하 는 최대 범위를 표시하면 〈Fig. 5〉와 같다. 핸드볼 골대의 안쪽 면은 가 로 $3 \mathrm{~m}$, 세로 $2 \mathrm{~m}$ 이다. 골키퍼가 만약 모든 슈팅을 보고 즉각적으로 반응 하여 모든 공을 막을 수 있다고 가정하면 골키퍼는 골대의 실제 가로 길 이보다는 좁은 범위를 방어하여도 되지만 세로의 경우 골대보다 높은 범 위도 방어해야 한다. 또한 골키퍼는 본인이 위치한 곳을 기준으로 먼 쪽 골대로 공이 날아올 경우 가까운 쪽 골대로 공이 날아올 때보다 상하로 보다 넓은 범위를 방어해야 한다.

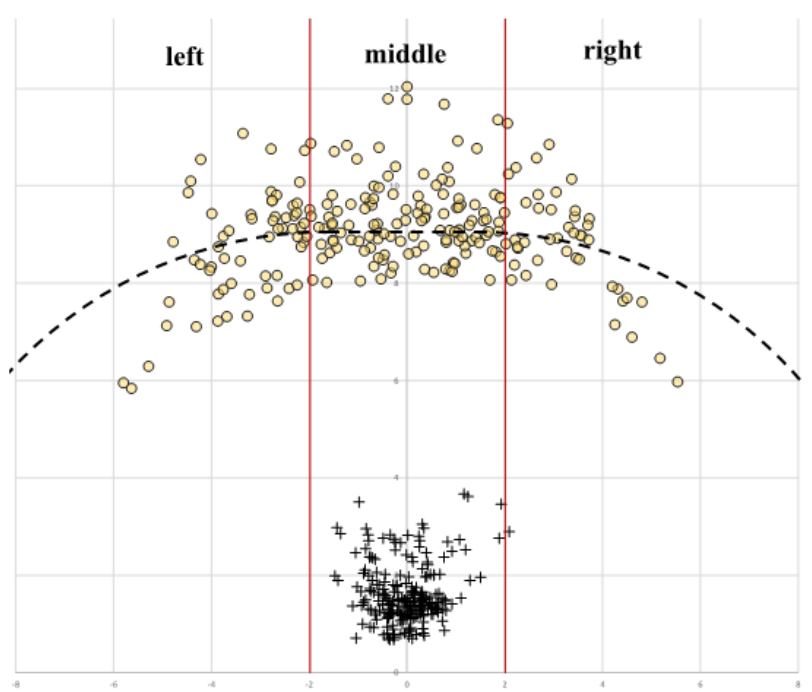

Fig. 4. The goalkeeper and the ball position in a $9 \mathrm{~m}$ jump shot
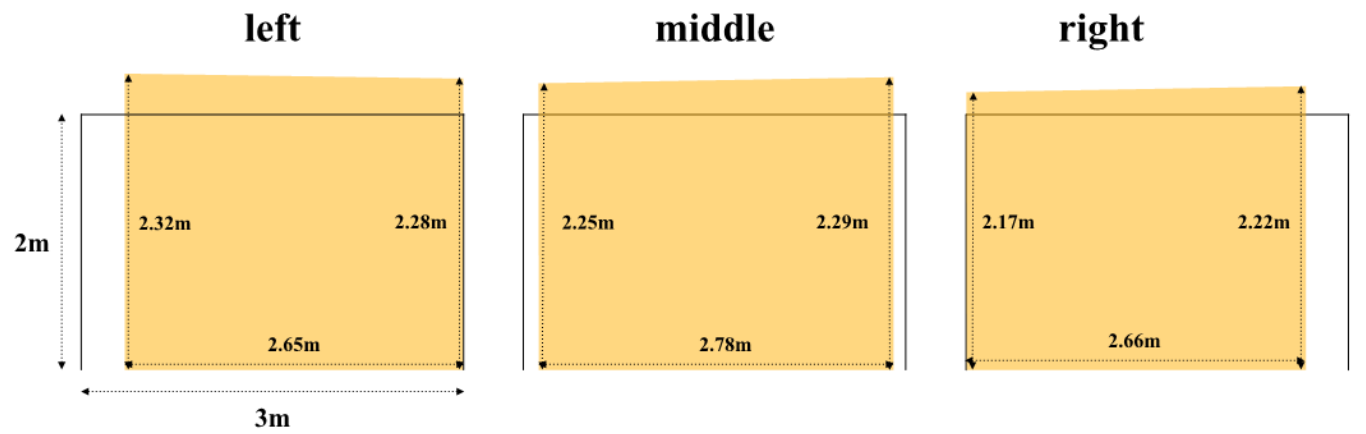

Fig. 5. Shooting range from a $9 \mathrm{~m}$ jump shot compared to a handball goalpost 
Table 1. Defense range (width and height) of the goalkeeper in $9 \mathrm{~m}$ jump shot

\begin{tabular}{|c|c|c|c|c|c|c|c|c|}
\hline \multicolumn{2}{|c|}{ Group } & $\begin{array}{l}\text { GK distance } \\
\text { (m) }\end{array}$ & $\begin{array}{c}\text { GK angle } \\
\left({ }^{\circ}\right)\end{array}$ & $\begin{array}{c}\text { Shoot distance } \\
\text { (m) }\end{array}$ & $\begin{array}{c}\text { Shoot angle } \\
\left({ }^{\circ}\right)\end{array}$ & $\begin{array}{c}\text { IDA_W } \\
(\mathrm{m})\end{array}$ & $\begin{array}{l}\text { IDA_h1 } \\
(\mathrm{m})\end{array}$ & $\begin{array}{c}\text { IDA_h2 } \\
\text { (m) }\end{array}$ \\
\hline \multirow{4}{*}{$\begin{array}{c}\text { Middle } \\
\text { shoots } \\
(\mathrm{n}=127)\end{array}$} & Mean & 1.590 & 9.000 & 9.385 & 6.157 & 2.475 & 2.069 & 2.070 \\
\hline & SD & 0.594 & 6.887 & 0.811 & 3.496 & 0.198 & 0.054 & 0.054 \\
\hline & Max & 3.570 & 35.890 & 12.041 & 13.415 & 2.777 & 2.289 & 2.250 \\
\hline & Min & 0.705 & 0.045 & 8.101 & 0.007 & 1.848 & 1.922 & 1.925 \\
\hline \multirow{4}{*}{$\begin{array}{c}\text { Right } \\
\text { shoots } \\
(\mathrm{n}=60)\end{array}$} & Mean & 1.768 & 23.458 & 9.395 & 20.888 & 2.267 & 2.068 & 2.044 \\
\hline & $\mathrm{SD}$ & 0.610 & 8.503 & 0.872 & 7.601 & 0.244 & 0.075 & 0.053 \\
\hline & Max & 3.627 & 55.651 & 11.576 & 44.255 & 2.660 & 2.217 & 2.169 \\
\hline & Min & 0.776 & 12.016 & 8.015 & 11.003 & 1.573 & 1.887 & 1.913 \\
\hline \multirow{4}{*}{$\begin{array}{c}\text { Left } \\
\text { shoots } \\
(\mathrm{n}=44)\end{array}$} & Mean & 1.909 & 22.942 & 9.466 & 20.574 & 2.230 & 2.051 & 2.083 \\
\hline & SD & 0.779 & 8.309 & 0.816 & 7.338 & 0.320 & 0.067 & 0.085 \\
\hline & Max & 3.955 & 42.024 & 11.470 & 42.845 & 2.646 & 2.280 & 2.322 \\
\hline & Min & 0.835 & 5.688 & 8.145 & 10.318 & 1.325 & 1.838 & 1.820 \\
\hline
\end{tabular}

\section{논의 및 결론}

본 연구는 제 99회 전국체육대회 남자 핸드볼 일반부 예선 7경기에서 나타난 231 개의 $9 \mathrm{~m}$ 슛을 통해 핸드볼 골키퍼의 실제 방어범위를 산출 하고 이를 통해 핸드볼 골키퍼 훈련에 도움을 주고자 하는 데 그 목적이 있다. 핸드볼 골대의 규격은 좌우폭(가로) $3 \mathrm{~m}$, 상하폭(세로) $2 \mathrm{~m}$ 이지만 그 골대를 방어하는 골키퍼는 골대의 규격대로 방어하는 것이 아니라 좌 우폭의 경우 골대의 규격보다 작게, 상하폭의 경우 골대의 규격보다 큰 움직임의 범위를 가져야 한다는 것을 확인하였다. 또한 측면의 공격을 방어하는 경우, 골키퍼는 본인 위치에서 가까운 쪽 골대의 상하 방어범 위보다 먼 쪽에 골대의 상하 방어범위가 더 넓다는 것을 알 수 있다.

핸드볼 골키퍼가 실점을 하지 않기 위해 방어해야 하는 방어범위는 슛 시점에서 골대, 골키퍼, 공의 상대적인 위치에 따라 결정된다. 그 중에서 도 공의 높이와 골키퍼의 전후방 위치가 골키퍼 방어범위의 상하폭과 좌 우폭을 좌우하는데 큰 영향을 미친다. 231 개의 $9 \mathrm{~m}$ 슛을 방어하면서 골 키퍼는 골라인에서 평균적으로 $1.697 \mathrm{~m}(\mathrm{SD}=.647)$ 앞에서 방어를 시도 하였는데, 골키퍼의 위치가 이보다 더 전방으로 나간다면 방어범위의 좌 우폭은 줄어들겠지만 상하폭은 증가한다. 따라서 골키퍼의 전후방 움직 임에 대한 trade-off를 이해하고 골키퍼가 좋은 경기력을 발휘할 수 있 도록 상대팀과 골키퍼의 특성을 고려하여 골키퍼의 전후방 위치를 잡는 것이 중요하다.

슈팅이 이루어지는 시점에서 공의 높이가 높아지면 골키퍼 방어범위 의 좌우폭은 동일하지만, 상하폭은 증가할 것이다. 점프슛은 핸드볼 경 기에서 발생하는 전체 슈팅의 대부분을 차지하고 슈팅이 이루어지는 타 점은 공격수의 신장이 클수록, 점프력이 높아질수록 높이가 높아진다. 따라서 골키퍼 훈련에 있어 상대팀 공격수의 신장과 점프력이 높아질수 록 골키퍼의 방어범위 중 상하폭이 좌우폭보다 비중이 커지는 것을 염두 해야 한다. 예를 들면 평균 신장이 큰 국외 선수들의 슈팅을 대비한 골키 퍼 연습의 경우, 높은 타점의 슈팅을 구현하기 위해 국내 선수들이 발판 의 도움을 받아 높이 점프하여 신장이 큰 국외 선수들의 슈팅을 모사하 게 된다.
핸드볼 골키퍼의 경기력을 향상시키기 위한 윤성원(2009)의 연구에 서는 골키퍼가 공격수의 공을 보다 잘 방어하기 위해 골대 안쪽의 모든 지점에 빠르게 도달하는 것이 경기력을 향상시키는 방법이라 생각하였 다. 이에 따라 골대의 좌우폭인 $3 \mathrm{~m}$ 와 상하폭인 $2 \mathrm{~m}$ 로 이루어진 직사각 형 범위의 모서리에 빨리 도달하는 방식으로 골키퍼 순발력을 측정하였 으며, 동일한 방식으로 순발력 훈련을 하였다. 핸드볼 골키퍼가 뛰어난 민첩성과 순발력을 가지고 있는 것은 방어에 유리하지만, 보다 효율적인 골키퍼 훈련을 위해서는 골대의 범위인 $3 \mathrm{~m} \times 2 \mathrm{~m}$ 를 골키퍼의 민첩성, 순발력 훈련의 범위로 잡는 것이 아니라 가로는 그보다 좁게, 세로는 그 보다 더 길게 골키퍼 방어 훈련을 실시하는 것이 보다 실질적이고 효율 적인 훈련법이 될 것이라 사료된다.

또한, 핸드볼 골키퍼에 대한 기존의 연구에서 골키퍼의 방어 위치, 골 키퍼의 방어 자세, 골키퍼 위치에 따른 방어범위의 면적 등을 고려할 때, 골키퍼 방어범위의 좌우측 높이를 동일한 것으로 가정하였다(양종 현, 2014; 양종현, 천영진, 2015; 양종현 외, 2019). 하지만 측면에서 슛 이 발생할 때는 골키퍼 방어범위의 좌우측 상단의 높이에 차이가 발생한 다는 것을 본 연구를 통해 확인하였다. 따라서 측면에서 슛이 발생한다 고 가정하였을 경우, 핸드볼 골키퍼는 먼 쪽 골대의 상단으로 향하는 슛 을 막을 때 가까운 쪽 골대의 상단으로 슛이 날아올 때보다 높은 도약이 필요하다는 사실을 인지한다면 핸드볼 훈련이나 경기 상황에서 방어율 을 높이는 데 도움이 될 것이다. 다양한 핸드볼 슛 중 $9 \mathrm{~m}$ 점프 슛은 상대 적으로 골키퍼에게 유리한 슛이며, 슈터는 이러한 상황을 극복하기 위해 더 많은 전략을 세워야 한다(Hatzimanouil et al., 2017). 본 연구의 결 과를 활용하면 슈터는 $9 \mathrm{~m}$ 점프 슛 시 먼 쪽 골포스트 방향으로 슈팅을 하는 것이 슛 성공률을 높일 수 있는 방법이라는 것을 알 수 있다.

본 연구에서는 골라인 중앙을 기준으로 좌우측 45 도 외곽에서 발생하 는 슈팅, 오버슛처럼 포물선 궤적을 그리는 슈팅, 중력과 공의 회전처럼 슈팅궤적에 주는 영향력 등은 고려하지 않고 공은 직선운동을 한다고 가 정하였다. 실제 핸드볼 경기 상황에서는 종종 오버슛이 발생하거나 강한 회전에 의해 공의 궤적이 급격하게 변하는 경우가 발생하기도 한다. 이 처럼 특수한 유형의 슈팅에 대해서는 추후 연구를 통해 다른 골키퍼 방 
어 전략을 찾을 필요가 있다.

골키퍼의 방어율은 팀 승리에 영향을 미친다(Rogulj, 2000; Skarbalius et al., 2013). 팀 승리를 이끌어 내기 위해 실전과 같은 골키 퍼 훈련이 필요하다. 본 연구의 결과를 통해 골키퍼는 방어율을 올리고 공격수는 골 성공률을 높이는 데 들이는 노력이 더욱 효과적이고 효율적 으로 될 수 있도록 기대한다.

\section{참고문헌}

교육과학기술부 (2012). 체육수업 보완지도자료 개발 - 보급: 핸드볼 지도서/ 지도안. 서울: 서울특별시교육청.

김의진 (1995). 과학적인 핸드볼. 대한체육회 스포츠과학연구소. 서울: 태창 인쇄소.

김재희 · 김지태 · 조남흥 (2015), 축구 골키퍼의 경기 중 행동기술요인 분석. 체육과학연구, 26(1), 153-162.

스포츠과학연구소 (1984). 과학적인 핸드보올. 대한체육회 스포츠과학연구 소. 서울: 태창인쇄소.

양종현 (2014). 골키퍼의 자세와 위치에 따른 방어 범위에 대한 연구. 미간행 박사학위논문. 서울대학교 대학원.

양종현 · 천영진 (2015). 핸드볼 페널티 드로우 시 방어율 향상을 위한 골키퍼 움직임 연구. 한국체육과학회지, 24(6), 1419-1428.

양종현 · 구도훈·이계산 (2019). $7 \mathrm{~m}$ 드로 시 여자 핸드볼 골키퍼의 이상적인 방어 위치 탐색. 한국체육학회지, 58(6), 441-447

윤성원 (2008). 베이징 올림픽 출전권 IHF 프랑스대회 참가보고서. 미간행 보 고서. 서울: 국민체육진흥공단 체육과학연구원.

윤성원 (2009). 핸드볼 골키퍼 방어율 향상을 위한 방어 동작기술과 체력 훈 련 프로그램 개발 및 적용 효과. 미간행 보고서. 서울: 국민체육진흥공 단 체육과학연구원.

이대택·이동우·윤성원 - 이명천 (2007). 축구이론총서-1; 축구트레이닝·코 칭. 서울: 대한미디어.

체육과학연구원 (2010). 체육지도자 훈련지도서: 핸드볼. 미간행 보고서. 서 울: 체육과학연구원.

추건이·김영년 (1984). 핸드볼 골키퍼의 트레이닝법. 서울: 동화출판사.

홍정호·박재현 (2016). 핸드볼경기의 포지션 별 경기력 평가요인과 중요도 분 석. 한국체육과학회지, 25(4), 1443-1454.

Abdel-Aziz Y. I., \& Karara H. M. (1971). Direct linear transformation from comparator coordinates into object space coordinates in close-range photogrammetry. ASP Symposium on Close-Range photogrammetry Illinois: Falls Church, 1-18.

Clanton, R. \& Dwight, M. P. (1996). Team Handball : steps to success. Champaign IL: Human Kinetics Publishers, Inc.

Hatzimanouil, D., Giatsis, G., Kepesidou, M., Kanioglou, A., \& Loizos, N. (2017). Shot effectiveness by playing position with regard to goalkeeper's efficiency in team handball. Journal of Physical Education and Sport, 17(2), 656.

Rogulj, N. (2000). Differences in situation-related indicators of the handball game in relation to the achieved competitive results of teams at 1999 world championship in Egypt. Kinesiology, 32(2), 63-74.

Skarbalius, A., Pukėnas, K., \& Vidūnaitė, G. (2013). Sport performance profile in men's European modern hand- ball: discriminant analysis between winners and losers. Education. Physical Training. Sport, 90(3), 44-54.

Sporis, G., Jukic, I., Ostojic, S. M., \& Milanovic, D. (2009). Fitness profiling in soccer: physical and physiologic characteristics of elite players. The Journal of Strength \& Conditioning Research, 23(7), 1947-1953. 
Walton, J. S. (1981). Close-rage cine-photogrammetry: a generalized technique for quantifying gross human motion. Unpublished Ph.D. Dissertation, Pennsylvania State University, University Park.

Yang, J. H., \& Lee, Y. S. (2016). A Study on the Defensive Stance and Position of Handball Goalkeepers : Facing a Forward Jump Shot Made from 9 Meters. Journal of Applied Biomechanics, 32(5), 504-512. doi:10.1123/jab.2015-0317

Yang, J. H., Park, Y. S., Kim, K. T., Ryu, J. K. (2017). A Goalkeeper's position for defending short range shots. International Journal of Sports Science \& Coaching, 12(5), 603-610. 


\title{
$9 \mathrm{~m}$ 점프 슛 상황에서 핸드볼 골키퍼 방어 범위에 대한 고찰
}

\author{
양종현' ${ }^{1}$ 권준우 ${ }^{2}$
}

1 인천대학교 교수

2 서울대학교 강사

[목적] 본 연구는 핸드볼 경기 중 발생하는 $9 \mathrm{~m}$ 점프 슛에 대하여 골대, 골키퍼, 공의 상대적 위치에 따라 골키퍼 방어범위 가 어떻게 변화하는지 알아보는 데 그 목적이 있다.

[방법] 제99회 전국체육대회 남자핸드볼 예선 7개 경기에서 발생한 231 개의 $9 \mathrm{~m}$ 점프 슛 상황에서 공이 슈터의 손에서 떨어지는 시점을 기준으로 골대, 골키퍼, 공의 위치를 파악하고 이를 통해 골키퍼의 방어범위를 산출하였다. 영상분석은 Kwon3D 3.01 프로그램을 사용하였고, 3차원 좌표의 계산은 DLT방법을 이용하였다.

[결과] 첫째, 실제 핸드볼 골대의 크기는 가로 $3 \mathrm{~m}$, 세로 $2 \mathrm{~m}$ 이지만 골키퍼의 실질적 방어범위의 가로는 골대의 너비보다 좁았고, 세로는 골대의 높이보다 높은 것으로 나타났다. 둘째, 골키퍼가 정면이 아닌 측면에서 공격수의 슈팅을 방어할 경우, 골키퍼가 위치한 곳에서 가까운 쪽 골대보다 먼 쪽 골대의 방어범위의 상하폭이 더 길었다.

[결론] 핸드볼 골키퍼의 방어범위는 슈팅 높이와 골키퍼의 방어 위치가 중요한 요인으로 작용하며, 특히 골키퍼 훈련에 있어 골키퍼의 좌우 움직임보다는 상하 움직임이 더 중요하다는 것을 알고 훈련에 임하는 것이 경기력 향상에 도움이 된 다는 것을 알 수 있다.

주요어

핸드볼, 골키퍼, 방어범위, $9 \mathrm{~m}$ 점프 숫 